\title{
The roles of the medial prefrontal cortex and hippocampus in a spatial paired-association task
}

\author{
Inah Lee ${ }^{1}$ and Frances Solivan \\ University of lowa, Department of Psychology, lowa City, lowa 52242, USA
}

\begin{abstract}
Although the roles of both the hippocampus and the medial prefrontal cortex (mPFC) have been suggested in a spatial paired-associate memory task, both areas were investigated separately in prior studies. The current study investigated the relative contributions of the hippocampus and mPFC to spatial paired-associate learning within a single behavioral paradigm. In a novel behavioral task, a pair of different objects appeared repeatedly across trials, but in different arms in a radial maze, and different rules were associated with those arms for reward. Specifically, in an "object-in-place" arm, the rat was required to choose a particular object associated with the arm. In a "location-in-place" arm, the animal was required to choose a certain within-arm location (ignoring the object occupying the location). Compared to normal animals, rats with ibotenic acid-based lesions in the hippocampus showed an irrecoverable impairment in performance in both object-in-place and location-in-place arms. When the mPFC was inactivated by muscimol (GABA $A_{A}$ receptor agonist) in the normal animals with intact hippocampi, they showed the same severe impairment as seen in the hippocampal lesioned rats only in object-in-place arms. The results confirm that the hippocampus is necessary for a biconditional paired-associate task when space is a critical component. The mPFC, however, is more selectively involved in the object-place paired-associate task than in the location-place paired-associate task. The current task powerfully demonstrates an experimental situation in which both the hippocampus and mPFC are required and may serve as a useful paradigm for investigating the neural mechanisms of object-place association.
\end{abstract}

Objects in the environment are usually remembered in association with particular locations. Object-in-place memory is universal across species and has been widely tested in rodents (Sziklas et al. 1996, 1998; Gaffan 1998; Gilbert and Kesner 2002, 2003, 2004; Eacott and Norman 2004; Hunsaker et al. 2006), nonhuman primates (Parkinson et al. 1988; Cahusac et al. 1989; Angeli et al. 1993; Malkova and Mishkin 2003; Rolls et al. 2005; Bachevalier and Nemanic 2008), and humans (Milner et al. 1997; Vargha-Khadem et al. 1997). An overall consensus in the literature is that the hippocampus is a critical structure for associating objects with locations (but see Malkova and Mishkin 2003).

In rodents, a challenging form of object-place pairedassociate learning has been tested by employing a biconditional association rule. Specifically, Gilbert and Kesner (2002) trained rats in a successive Go/No-Go task in which two object-place paired associates were reinforced. In this task, choosing a particular object A was rewarded only when it appeared in a particular location 1 , but not in location 2 , and object $B$ was only rewarded when it was associated with location 2 , but not with location 1 . It has been shown that lesions in the hippocampus produce severe deficits in both the acquisition and retention of this task although the lesioned animals improved their performance when retested after surgery (Gilbert and Kesner 2002, 2004). Within the hippocampus, the importance of the CA3 subfield, but not the dentate gyrus and CA1, has been implicated in the acquisition of this task (Gilbert and Kesner 2003), presumably due to the presence of an autoassociative network in CA3 that is ideal for making arbitrary associations (Marr 1971; McNaughton and Morris 1987; Rolls and Kesner 2006). In addition, the prefrontal cortex is also involved in the same type of object-place paired-associate learning (Kesner and Ragozzino 2003). The rats with lesions in the prelimbic/infralimbic areas of the medial pre-

'Corresponding author.

E-mail inah-lee@uiowa.edu; fax (319) 335-0191.

Article is online at http://www.learnmem.org/cgi/doi/10.1101/lm.902708. frontal cortex (mPFC) showed severe deficits in learning the same task. Kesner and Ragozzino suggested the complex, biconditional nature of their task as a reason for the deficits observed in the mPFC-lesioned rats because similar results had not been observed in simple conditional discrimination tasks involving Go/No-Go responses (Ragozzino et al. 1998, 2002). In sum, the object-place paired-associate paradigm provides a useful platform for investigating the functions of the hippocampus and mPFC.

Although prior studies investigated the functions of the hippocampus and mPFC in the spatial paired-associate task, both regions were studied independently in separate studies. Inspired by the well documented interactions between the two regions in a goal-based memory task (Floresco et al. 1997; Thierry et al. 2000; Lee and Kesner 2003a,b; Poucet et al. 2004; Doeller et al. 2005; Hyman et al. 2005; Jones and Wilson 2005; Kyd and Bilkey 2005; Wang and Cai 2006; Jo et al. 2007), the current study aims to examine the contributions of the hippocampus and mPFC "within" a newly designed, spatial paired-associate task and also using a "within-subject" manipulation of both areas. The task was designed to recruit both the hippocampus and mPFC by requiring rats to flexibly switch between two types of spatial paired-associate rules: an object-place paired-associate rule and a location-place paired-associate rule. To be successful in this task, the animal should first identify its spatial location (i.e., a specific arm in a radial maze) accurately in the environment because the retrieval of a correct rule (object-place association versus location-place association) is dependent on the arm location information.

We examined the relative contributions of the hippocampus and mPFC in this task by lesioning the hippocampus and implanting cannulae in the mPFC within subjects. If the hippocampus is critical in processing spatial information as extensively demonstrated in the literature (O'Keefe and Dostrovsky 1971; O'Keefe and Nadel 1978; Morris et al. 1982; Rolls et al. 1989; Gilbert and Kesner 2002; Hartley et al. 2003; Lee and Kesner 
2003a,b; Lee et al. 2005), damage in the hippocampus should lead to impairment in solving both the object-place and location-place paired-associate tasks because the animal is unable to correctly locate itself in the environment. With respect to the prefrontal cortical contribution, it has been suggested that the PFC is important for disambiguating conflicting rules and selecting appropriate responses (Granon et al. 1994, 1996 ; Granon and Poucet 1995; Hoshi et al. 1998, 2000; Kesner and Ragozzino 2003; Milham et al. 2003; Ragozzino et al. 2003; Haddon and Killcross 2006; Johnston et al. 2007; Mansouri et al. 2007). If the mPFC is inactivated in normal animals with intact hippocampi, the literature thus predicts impairment in applying the rules selectively and flexibly according to the spatial location information in the current task.

\section{Materials and Methods}

\section{Subjects}

Thirteen male Long-Evans rats (320-450 g) were housed individually in standard rodent cages. Twelve animals were originally used (six rats for both experimental and control groups), but one more rat was added later to the experimental group since one of the animals lost its cannulae after day 11 . They were maintained on a 12-h light-dark cycle and all behavioral experiments were conducted during the light phase of the cycle. For behavioral testing, each rat was initially food deprived to $80 \%$ of its freefeeding weight and allowed access to water ad libitum.

\section{Behavioral apparatus}

An elevated, radial arm maze made of black Plexiglas (Fig. 1A) was used throughout the experiment. The maze was composed of seven radial arms $\left(10 \times 80 \mathrm{~cm}\right.$ each, separated by $25.7^{\circ}$ from each other). The arms radiated from a circular center stage $(48 \mathrm{~cm}$ in diameter). The distal end of each arm was connected to a rectangular platform $(23 \times 30 \mathrm{~cm}$; henceforth "choice platform") in which objects were presented. Each choice platform contained three food wells $(2.5 \mathrm{~cm}$ in diameter each) separated from each other by transparent vertical dividers (Plexiglas; each $6 \times 13 \mathrm{~cm}$; Fig. 1A, inset). The transparent dividers were placed to encourage more explicit and targeted responses to discrete food wells. A transparent guillotine door $(10 \times 25 \mathrm{~cm})$ was available at the entrance of each arm to allow access to the arm. A start box $(20 \times 25 \times 30 \mathrm{~cm})$ with an opaque guillotine door was located in the center stage. The maze was placed in the center of a testing room (100 square $\mathrm{ft}$ ) and the walls and ceilings of the room were decorated with distinctive visual cues (Fig. 1A). A CCD camera was positioned above the maze for recording behavioral experiments and two loud speakers were placed underneath the center stage of the maze to provide white noise during the behavioral experiments.

\section{Handling, familiarization and shaping}

Once naïve rats arrived, they were handled for one week. During the handling period, the animals were accustomed to eating sugar-coated cereal (Froot Loops, Kellogg's). The rats were then introduced to the behavioral testing room for familiarization. During the initial phase of the familiarization (approximately for 2-3 d), each rat was placed in the maze with all the doors open and cereal rewards randomly scattered throughout the maze. Once the rat started to move and eat cereal comfortably in the maze for $30 \mathrm{~min}$, a more specific way of retrieving food was taught for $\sim 3-4 \mathrm{~d}$. For this, the rat was first placed in the start box of the maze with its door closed. The doors of all arms were closed except for the one that was chosen randomly. In the choice platform attached to the open arm, a black junk object
A.

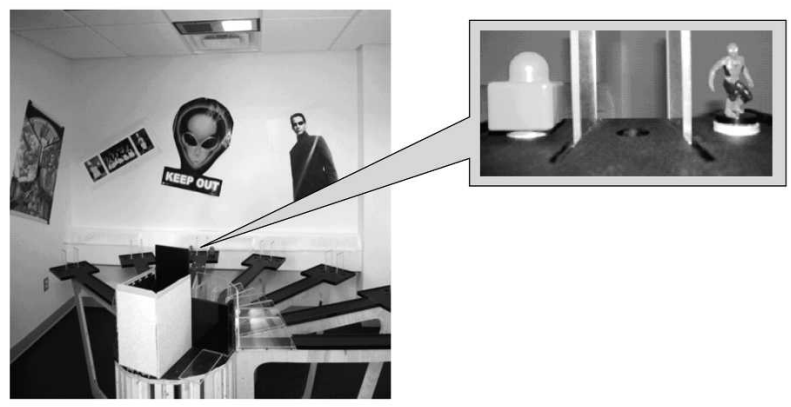

B.

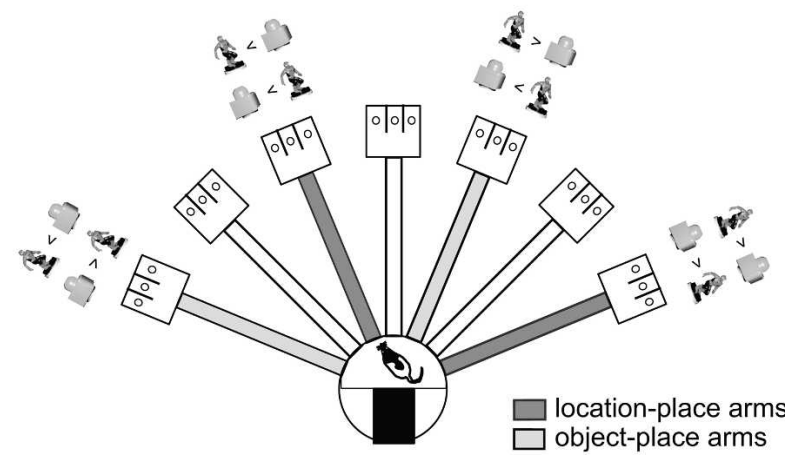

Figure 1. Behavioral apparatus and testing environment. (A) Radial maze in a testing room with distinct visual cues. (Inset) Two objects, a LEGO block and a Spider-Man, positioned over left and right food wells, respectively, in the choice platform. The transparent partitions between food wells were to encourage discrete choices between objects. (B) Spatial paired-associate learning task. Illustration of the radial maze (overview) is given with four arms (arm 1, 3, 5, and 7 clockwise) used in the task in gray color. Arms 1 and 5 (lighter gray) were used for object-place paired-associate trials and arms 3 and 7 (darker gray) were used for location-place paired-associate trials. Possible configurations of objects and appropriate choices are provided for individual arms (e.g., LEGO block results in reward in arm 3, regardless of its position in the choice platform) all together for illustrative purposes only. In each trial, only one arm was accessible and objects were available only in the open arm.

with a heavy washer attached at the bottom covered the center food well in which a quarter piece of cereal reward was hidden. The washer attached to the object completely covered the food well, thus preventing the animals from smelling food even in the vicinity of the object. When the start box door was opened by an experimenter, the rat was trained to come out of the start box, enter the opened arm, and retrieve the cereal reward by displacing the overlying object. After the animal retrieved the cereal from the food well, the experimenter gently guided the animal to the start box so that the animal consumed the food reward in the start box. After a few days of training, rats voluntarily return to the start box normally for eating the reward with minimal guidance by the experimenter. This was helpful because it minimized the variability in the amount of exposure to the environment among the rats after they grabbed the cereal reward from the food well. We take advantage of the rat's natural tendency that, if the size of the cereal reward is big enough, rats prefer to eat the food reward inside a secure place (i.e., the start box in our maze) instead of eating it in an open space (e.g., choice platform). Once the rat was able to repeat this food-retrieving routine for 32 times within $30 \mathrm{~min}$, the animal was considered ready for the behavioral task described below. 


\section{Behavioral training}

Four arms (e.g., arms 1, 3, 5, and 7 clockwise in Fig. 1B) of the maze were used in the current task. In each trial, when the start box door was opened by the experimenter in the testing room, the rat came out of the start box and entered one of the four arms (only one arm was open in the maze in a given trial throughout the experiment and objects were presented only in that open arm). The rat then ran along the arm and reached the choice platform at the end. Two food wells (i.e., left and right food wells; the middle food well was never used in the task) of the choice platform were occupied by toy objects (i.e., a Spider-Man and a LEGO block). The locations of the toy objects in a given choice platform were counterbalanced across trials (Fig. 1B). The rat needed to make a choice for one of the objects in the choice platform by displacing the object to uncover the food well. The two objects were chosen because no innate preference for either object was previously observed in rats in our laboratory.

To make a correct choice for reward, the animal must learn the rule associated with a particular arm (Fig. 1B). Specifically, the rat must choose a particular "object" in arm 1 (LEGO block) and arm 5 (Spider-Man) irrespective of the location (i.e., left or right food well) of the rewarding object within the choice platform. Since this requires the rat to associate a particular place in the maze (i.e., arm 1 or arm 5) with certain object information (i.e., LEGO block or Spider-Man), this rule will be operationally defined as "object-place paired association," henceforth. In addition, the animal needed to choose a particular food well location (i.e., left or right food well in the choice platform) irrespective of the object occupying the rewarding food well in arm 3 (right food well) and arm 7 (left food well). This rule requires the association between two different spatial variables (i.e., a certain arm and a food well location within its choice platform) and thus will be operationally defined as "location-place paired association," henceforth. When the rat made a correct choice, the animal came back to the start box and consumed the reward in the start box (with the start box door closed) while the experimenter prepared for the next trial. A wrong choice in the choice platform was punished by preventing the animal from correcting its response by blocking the rat with a small Plexiglas panel $(10 \times 25$ $\mathrm{cm})$ and guiding the animal to the start box with no food reward.

Thirty-two trials were given per day with an intertrial interval of 20-40 sec between trials. For each trial, the latency from entering an arm to displacing an object in the choice platform was measured on the basis of video recorded during the experiment. The locations of objects in the choice platform and the left and right responses associated with correct choices were all counterbalanced across trials. The sequence of visiting different arms was pseudorandomized and two different sequences were alternately used between days to prevent the rats from possibly remembering a particular sequence of responses when only a single sequence of trials is used repeatedly. After training to a criterion ( $\geq 75 \%$ correct choices for all four arms for two consecutive days), each rat received surgery (see below). It took $\sim 2-3$ wk on average for the animals to learn the task to criterion before surgery.

\section{Surgery}

Each rat was implanted bilaterally with guide cannulae (22gauge) coupled with stylets (28-gauge, $1 \mathrm{~mm}$ protrusion from the tip of the guide cannula) targeting the mPFC. In a subset of those rats, bilateral lesions were made in the entire hippocampus with multiple injections of ibotenic acid $(10 \mathrm{mg} / \mathrm{mL}, 0.3 \mu \mathrm{L} / \mathrm{site}$ at 10 $\mu \mathrm{L} / \mathrm{h}$ ) using a $10-\mu \mathrm{L}$ Hamilton syringe (Hamilton) operated by a microinjection pump (Cole-Parmer). Detailed surgical procedures are as follows. Each animal was deeply anesthetized under isoflurane in an induction chamber. The animal was then in- jected with Ketamine $(60 \mathrm{mg} / \mathrm{kg})$ and Xylazine $(8 \mathrm{mg} / \mathrm{kg})$ intraperiotoneally and placed in a stereotaxic instrument (Stoelting), and an incision was made along the midline of the scalp. The anesthesia was maintained by isoflurane afterward throughout surgery. The skull was exposed and the instrument was adjusted to ensure a flat skull surface. Small burr holes were drilled in the skull and ibotenic acid injection and cannulae implantations were made using the following coordinates: (1) hippocampal lesions: (a) $3.1 \mathrm{~mm}$ posterior to bregma, $1.8 \mathrm{~mm}$ lateral to midline, and $3.7 \mathrm{~mm}$ ventral from the skull surface, (b) $4.3 \mathrm{~mm}$ posterior to bregma, $3.2 \mathrm{~mm}$ lateral to midline, and $3.7 \mathrm{~mm}$ ventral from the skull surface, and (c) $5.2 \mathrm{~mm}$ posterior to bregma, $5.0 \mathrm{~mm}$ lateral to midline, and $6.8 \mathrm{~mm}$ ventral from the skull surface; (2) mPFC cannulae: $2.7 \mathrm{~mm}$ anterior to bregma, $1.5 \mathrm{~mm}$ lateral to midline, and $4.9 \mathrm{~mm}$ ventral from the skull surface with $10^{\circ}$ angle from a vertical midline. For the injection of ibotenic acid, the injection needle (30-gauge cannula) was left in place $1 \mathrm{~min}$ before and after the injection to ensure the proper diffusion of the neurotoxin in the target site. Seven rats (HP-LES group) received the axon-sparing, neurotoxic lesions in the hippocampus, and six rats (HP-CTRL group) underwent sham lesions with phosphate-buffered saline (SAL) injections in the hippocampus (the assignment of the lesion group was done randomly). As mentioned above, both HP-LES and HP-CTRL groups also received the implantation of bilateral cannulae in the mPFC. For this procedure, small burr holes were drilled in the periphery of the skull for positioning jeweler's screws (0-80). After the insertion of the bilateral cannulae in the mPFC, bone cement (Zimmer) was used around the skull screws and the cannulae to ensure firm implementation. For the HP-LES group, Diazepam (20 mg/kg, i.p.) was injected postoperatively to prevent possible seizure activity. Body temperature was maintained by a heating pad in all animals after surgery. All protocols conformed to the NIH Guide for the Care and Use of Laboratory Animals and the Institutional Animal Care and Use Committee at the University of Iowa.

\section{Behavioral testing after surgery}

After a week of recovery, the rats were retested for $10 \mathrm{~d}$ (day 1-10) in the spatial paired-associate task in the same environment. This was to test the effect of the hippocampal lesions. From day 11, either SAL or muscimol (MUS; $0.2 \mu \mathrm{g} / 0.2 \mu \mathrm{L}$ per site at $10 \mu \mathrm{L} / \mathrm{h}$ ) was injected $30 \mathrm{~min}$ before the behavioral testing for $4 \mathrm{~d}$ (day 11-14) with the following schedule: day 11, SAL; day 12 and 13, MUS; and day 14, SAL. For this procedure, immediately after the drug injection each day, the rat was returned to its home cage and any abnormality in movement from the drug injection was carefully examined for $30 \mathrm{~min}$ before the rat was placed on the maze for testing. One of the rats from the HP-LES group lost the cannulae after day 11 and was not included in the data analysis for the drug-injection experiment and a simple objectdiscrimination task that followed the drug-injection phase (see below). Experimenters were blind to the surgical manipulations and drug-injection conditions of the animals at the time of behavioral testing throughout the experiments.

\section{Simple object-discrimination task}

After testing the animals in the main task, the rats were trained and tested with a simple object-discrimination task (Fig. 7A, see below) from day 15 to exclude the possibility of any generic impairment (e.g., sensory-motor deficits) in the lesioned rats as well as in drug-injected animals. In this task, only a single arm (i.e., arm 4) that had not been used in the original task was used. Specifically, when the start box door was opened, the rat ran down the arm and encountered two toy objects (i.e., a toy kid and an oil can) that were different from the ones used for the 
original task. No innate preference for either object was previously observed in rats in our laboratory. The toy-kid object was always rewarded. Importantly, this task did not require the rat to consider the arm location information to make correct choices between different objects. Instead, the rat could obtain the reward by simply following the toy kid in this task. Left and right positions of the objects were counterbalanced between trials. As in the original paired-associate task, 32 trials were given per day with an intertrial interval of $20-40 \mathrm{sec}$ between trials. All rats were trained until they showed $\geq 75 \%$ correct choices for two consecutive days. All rats learned this task very quickly and it took only $2-3$ d for them to reach the criterion performance level. Once they reached criterion, either SAL or MUS was injected for $4 \mathrm{~d}$ with the same schedule (i.e., SAL-MUS-MUS-SAL) used in the spatial paired-associate task described above.

\section{Histology}

Histological verifications of cannula positions and lesions were performed after the completion of all behavioral experiments. Rats received a lethal dose of sodium pentobarbital (Euthasol, Henry Shein), followed by a transcardial infusion of $0.9 \%$ saline and a $10 \%$ formaldehyde solution. Each brain was stored in a $10 \%$ formalin- $30 \%$ sucrose solution at $4^{\circ} \mathrm{C}$ for $72 \mathrm{~h}$. The brains were frozen, cut in coronal sections $(40 \mu \mathrm{m})$ on a sliding microtome (Microm, Thermo Fisher Scientific), and later stained with thionin (Sigma).

The amount of damage in the hippocampus was threedimensionally visualized and quantified for each rat, using computer software (Gilbert et al. 2001; Lee and Kesner 2003a,b, 2004). For this procedure, the brain sections were digitally captured via Photoshop (Adobe systems, Inc.) and the boundaries of the major cell layers in the hippocampus (i.e., pyramidal cell layers in CA regions and granule cell layers in the dentate gyrus) were drawn using a pen tablet as an input device (Wacom). This was performed in tandem with the examination of the original slides under the microscope at high magnification $(\geq \times 40)$ for accurate delineations of the intact cell boundaries. The twodimensional images of the cell layers delineated were detached as separate image layers from the original, digital section images in Photoshop and converted to black-and-white bitmap images. The serial sections of bitmap images were then threedimensionally reconstructed (Voxwin). Comparing the number of voxels used for reconstructing the hippocampus in the HP-LES and HP-CTRL groups provided a volumetric estimation of the damage produced in the hippocampus by ibotenic acid. Furthermore, visualizing the intact cell layers in the HP-LES group also provided the locations of intact tissues within the hippocampus.

\section{Results}

\section{Histology}

Figure 2 illustrates the cannula positions in $\mathrm{mPFC}$ and the extent of neurotoxic lesions in the hippocampus. As shown in Figure $2 \mathrm{~A}, \mathrm{~B}$, the tips of the injection needles used for cannulae were located in the prelimbic and infralimbic areas of the PFC. Figure 2C,D shows the extent of neurotoxic lesions in the hippocampus. The HP-CTRL group showed no damage in the hippocampus, whereas most of the dorsal and ventral areas of the hippocampus were eliminated by ibotenic acid in the HP-LES group. No damage in other extrahippocampal areas (e.g., entorhinal cortex and subiculum) was visible under microscopic examination. In both control and lesion groups, minor damage was observed in overlying cortices above the dorsal hippocampus due to the penetration of those areas by the injection needle (Fig. 2C). The intact cell layers where principal cells (i.e., pyramidal neurons in $\mathrm{CA}$ regions and granule cells in the dentate gyrus) were identified
A.
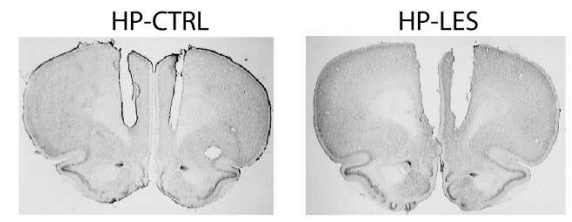

B.

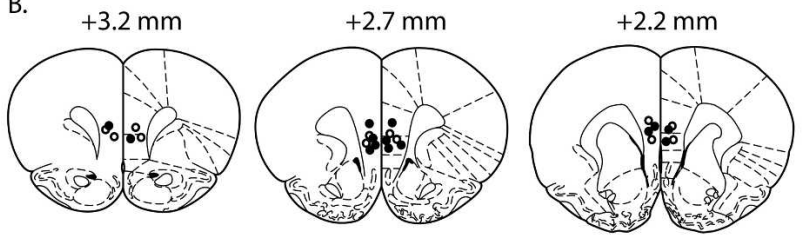

C.
C. HP-CTRL
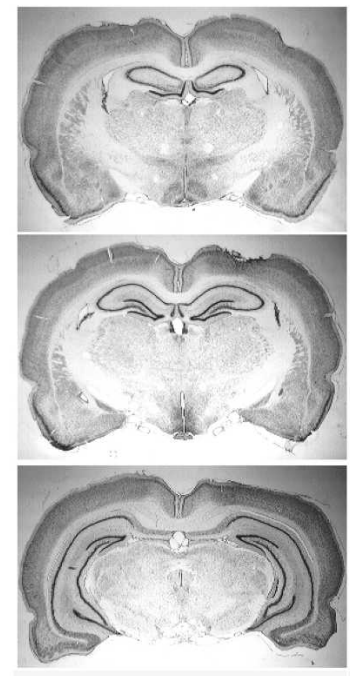

D.

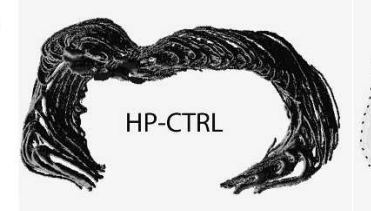

HP-LES
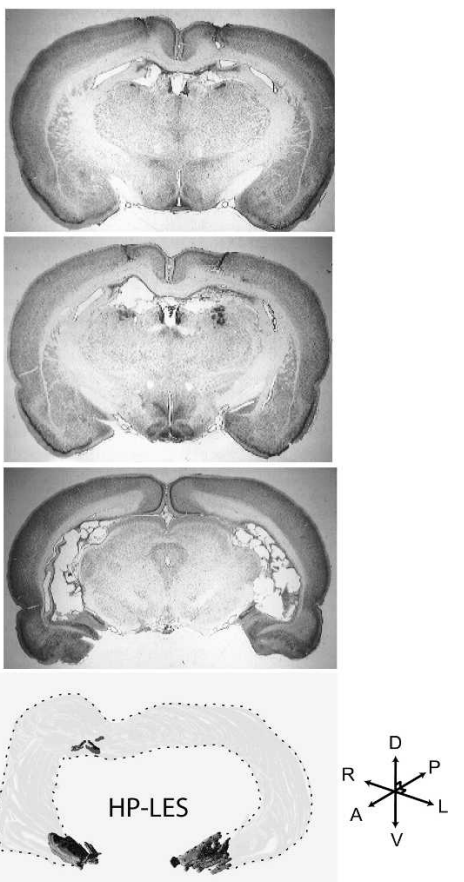

Figure 2. Cannula positions and the extent of hippocampal lesions. $(A)$ Histological verifications of the cannula positions in MPFC in the HP-LES and HP-CTRL groups. (B) Illustration of the positions of the injection cannula tips in mPFC (O, HP-CTRL group; $\bullet$, HP-LES group). The anterior-posterior stereotaxic coordinates of sections are given by the numbers above the sections. Illustrations are modified from Paxinos and Watson (1986). (C) Histological verifications of the hippocampal and control lesions. Three different sections along the anterior-posterior axis are shown to demonstrate the full extent of lesions in both dorsal and ventral hippocampal regions in the HP-LES group. The HP-CTRL group showed intact hippocampi. (D) Examples of three-dimensionally reconstructed cell layers in the intact hippocampus (HP-CTRL group) and lesioned hippocampus (HP-LES group), providing a dorsolateral view of the reconstructed image (see orientation arrows). Remaining cell layers from the HP-LES group were superimposed on the control group's image (light gray) for illustrative purposes. Compared to the control-lesioned hippocampus, the neurotoxic lesions of the hippocampus only left minor cell layers at the dorsal and ventral tips in the whole hippocampus.

under microscopic examination were three-dimensionally reconstructed (Fig. 2D). Compared to the control-lesioned animals, the rats with neurotoxic lesions exhibited massive damage in the entire hippocampus although the most anterior tips of the dorsal and ventral areas of the hippocampus were spared in some rats (Fig. 2D). The numbers of voxels for the three-dimensionally re- 
constructed hippocampi in the HP-CTRL and HP-LES groups were significantly different $(P<0.05$, Mann-Whitney $U$-test); five rats in the HP-LES group showed $\geq 90 \%$ damage and two other rats exhibited $70 \%-80 \%$ damage in the hippocampus, compared to the average hippocampal volume of the HP-CTRL group.

\section{Effects of the hippocampal lesions on performance}

When the animals were retested in the task after surgery, the HP-CTRL and HP-LES groups demonstrated a marked difference in their overall performance (Fig. 3A). When the overall percent correct scores (i.e., combining object-in-place and location-inplace arms) were compared between the two groups across $10 \mathrm{~d}$ of post-surgical testing, the HP-CTRL group showed $\geq 80 \%$ correct performance throughout the testing period. In contrast, the performance of the HP-LES group remained at the near chance level throughout $10 \mathrm{~d}$, demonstrating that the hippocampus is a necessary structure for successful performance in the current task. An ANOVA with a repeated measures design showed significant effects of the lesion group $\left(F_{(1,11)}=153.1, P<0.0001\right)$ and postsurgical day $\left(F_{(9,99)}=2.6, P<0.01\right)$, whereas no significant interaction between the two variables was observed $\left(F_{(9,99)}=0.9\right.$, $P=0.5$ ).

The overall pattern of performance was similarly observed when the data from the location-place association trials (arms 3 and 7; Fig. 3B) and those from the object-place association trials (arms 1 and 5; Fig. 3C) were separately analyzed. When the rats needed to visit particular food well locations associated with different arms (location-place paired association), the HP-CTRL group showed $\geq 90 \%$ correct performance throughout the postsurgical testing (Fig. 3B). The HP-LES group exhibited $\leq 60 \%$ correct performance during the earlier testing period and slightly improved their performance in the later phase of testing. In the arms where object-place paired associations were relevant (Fig. 3C), the HP-CTRL group started at approximately their presurgical criterion level (i.e., 75\% correct performance) and gradually
A.

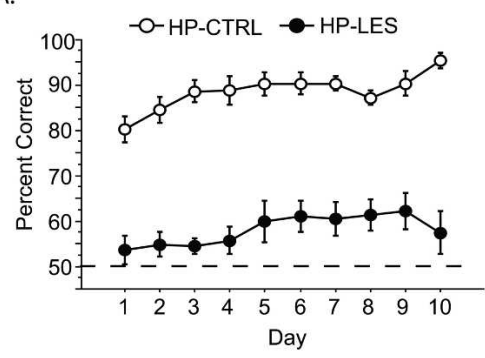

C.

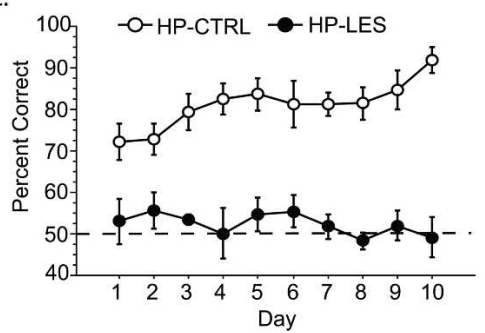

B.

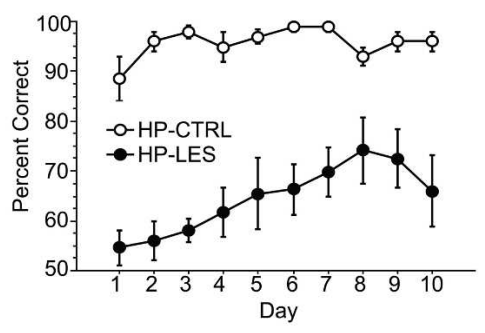

D.

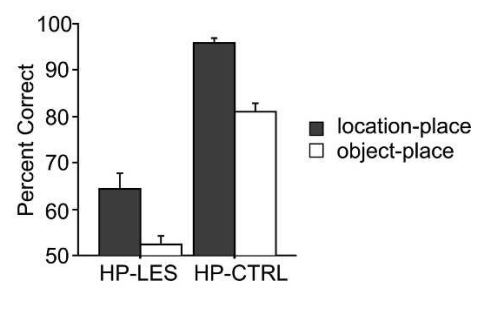

Figure 3. Post-surgical performance. ( $A$ ) Overall performance (location-in-place and object-in-place arms combined) across $10 \mathrm{~d}$ of testing. The dotted line shows the chance level of performance. $(B)$ Performance for location-in-place arms for $10 \mathrm{~d}$ after surgery. (C) Performance for object-in-place arms for $10 \mathrm{~d}$ after surgery. The dotted line shows the chance level of performance. (D) Data shown in $B$ and $C$ are reorganized to show differences in performance between location-in-place and object-in-place arms within each lesion group. HP-CTRL, control lesion group; HP-LES, neurotoxic lesion group. All graphs show mean \pm SEM. improved their performance across $10 \mathrm{~d}$. However, the HP-LES group continuously remained at the chance level with no improvement throughout the post-surgical testing.

An ANOVA with repeated measures was performed with the lesion group as a between-subject variable and the postsurgical testing day and the two rules (location-place and object-place paired associations) as two within-subject variables. The results showed highly significant effects of the lesion group $\left(F_{(1,11)}=142.2, P<0.0001\right)$ and the rule $\left(F_{(1,11)}=59.9\right.$, $P<0.0001)$, as well as significant effects of the post-surgical testing day $\left(F_{(9,99)}=2.3, P<0.05\right)$ and the triple interaction among the rule and post-surgical testing day and lesion group $\left(F_{(9,99)}=2.6, P<0.01\right)$. Paired comparisons (paired $t$-test) of the performance between location-place and object-place pairedassociation rules (with percent correct scores averaged across 10 d) showed significant decreases in performance in object-in-place arms in both the HP-CTRL $(P<0.001)$ and HP-LES $(P<0.01)$ groups (Fig. 3D), suggesting that the object-place paired associations were more difficult than the location-place paired associa-

\section{Effects of the mPFC inactivation on performance}

After the $10 \mathrm{~d}$ of post-surgical testing, the same rats were tested in the task with SAL or MUS injections in the MPFC. As shown in Figure 4A, injecting SAL into the mPFC exerted no influence on the overall performance (i.e., object-in-place and location-inplace arms combined); that is, the HP-CTRL group showed $\geq 90 \%$ correct performance and the HP-LES group exhibited similar deficits to their previous performance during the $10 \mathrm{~d}$ of testing exerted little, if any, effect on the performance of the HP-LES group; that is, they maintained their poor performance with or without MUS injections. When MUS was injected for the first time in the MPFC in the HP-CTRL group, there was impairment in performance compared to the previous SAL-injected condition (Fig. 4A). The performance quickly improved, however, on the second day of MUS injection and returned to the normal performance level with SAL injection on the next day. According to an ANOVA with repeated measures, there were significant effects of the lesion group $\left(F_{(1,10)}=32.4, P=0.0002\right)$, druginjection day $\left(F_{(3,30)}=9.5, P=0.0001\right)$, and an interaction between the two variables $\left(F_{(3,30)}=3.5, P<0.05\right)$. Further paired comparisons (paired $t$-test) showed that the performance of the HPCTRL group significantly dropped between the first SAL and MUS injections in the first two days $(P<0.05)$ and significantly increased between the MUS and SAL injections in the last two days $(P<0.05)$. No significant difference was found between the two SAL injection conditions $(P>0.5)$ and between the two MUS injection conditions $(P>0.1)$ in the HP-CTRL group. In the HP-LES group, none of the paired comparisons between drug injection conditions were significant $(P$-values $>0.1)$. Paired comparisons between groups per each druginjection day revealed significant differences only in the two SAL conditions on the first and last days ( $P$-values $<0.05$ ). 
A

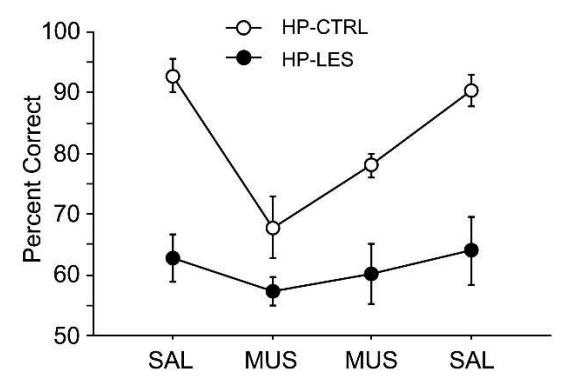

B.
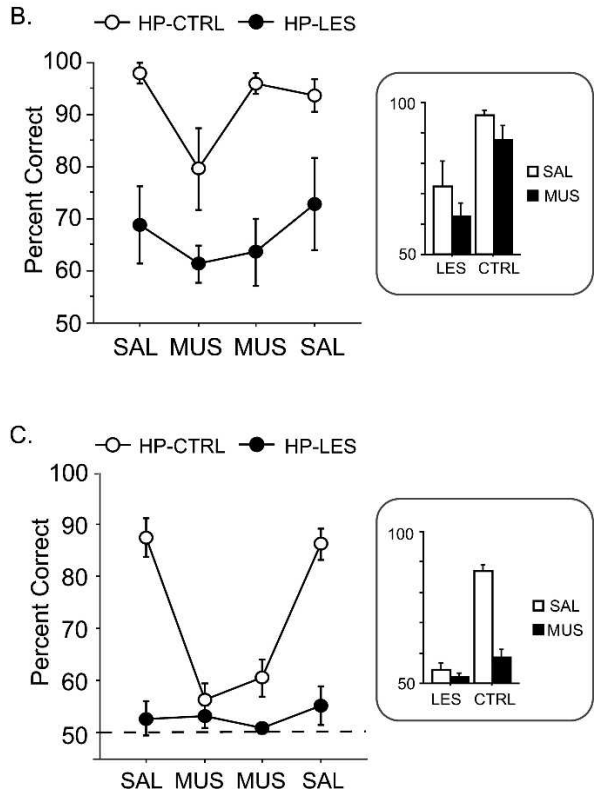

Figure 4. Performance with drug injections in the mPFC. $(A)$ Overall performance (location-in-place and object-in-place arms combined) for 4 $\mathrm{d}$ with either saline (SAL) or muscimol (MUS) injected in MPFC before testing in both lesion groups. (B) Performance for location-in-place arms for $4 \mathrm{~d}$ with SAL or MUS injection. (Inset) Data from the two SAL-injection days were averaged and the same was done for the two MUS-injection days. The graph shows the overall difference between SAL and MUS conditions within each lesion group. $Y$-axis, percent correct; LES, HP-LES group; CTRL, HP-CTRL group. (C) Performance for object-in-place arms only for $4 \mathrm{~d}$ with SAL or MUS injection. (Inset) Data were averaged as in $B$ for each lesion group. HP-CTRL, control lesion group; HP-LES, neurotoxic lesion group. All graphs show mean \pm SEM.

To better characterize the deficits shown in Figure 4A, the performance data associated with different rules (i.e., locationplace and object-place paired associations) were separately analyzed (Fig. 4B,C). In location-in-place arms (Fig. 4B), the HP-LES group showed $\sim 60 \%$ correct performance when SAL or MUS was injected although MUS injections appear to slightly lower performance. The HP-CTRL group showed almost perfect performance when SAL was injected. However, when MUS was injected for the first time, the performance of the HP-CTRL group dropped down to $\sim 80 \%$. It turns out that this was due to one of the animals in the HP-CTRL group showing $46 \%$ correct performance on that day while all the other rats showed $\geq 70 \%$ correct performance (thus exhibiting the relatively large error bar in Fig. 4B). On the second day of MUS injection, the HP-CTRL exhibited performance that was indistinguishable from the SAL conditions. Therefore, on average, it appears that MUS injections in the mPFC in the HP-CTRL group only minimally affected the overall performance in location-in-place arms (Fig. 4B, inset).
Importantly, MUS injections in the mPFC caused a marked difference in performance in the HP-CTRL group when the rats were to remember objects in association with their spatial locations (i.e., object-place paired association; Fig. 4C). Specifically, the performance level of the HP-CTRL group dropped down to $\sim 60 \%$ on both MUS-injection days, whereas the performance was maintained at near $90 \%$ with SAL injections before and after MUS injections. The performance of the HP-LES group remained at the chance level regardless of SAL or MUS injections.

An ANOVA was performed with a repeated measures design with the lesion group as a between-subject variable and the drug injection condition (SAL or MUS) and the rule (location-in-place vs. object-in-place) each serving as a within-subject variable. The results showed significant effects of the lesion group $\left(F_{(1,10)}=39.1, P<0.0001\right)$, the drug condition $\left(F_{(3,30)}=11.0\right.$, $P<0.0001)$, and the triple interaction among the lesion group and post-surgical testing day and drug injection condition $\left(F_{(3,30)}=6.3, P<0.01\right)$. Paired comparisons (paired $t$-test) between different drug conditions within the HP-CTRL group resulted in significant differences between the SAL and MUS injections in the first two days $(P<0.01)$ and between the following MUS and SAL injections in the last two days $(P<0.001)$. No significant difference was found between the two SAL injection conditions $(P>0.5)$ and between the two MUS injection conditions $(P>0.1)$ in the HP-CTRL group. No paired comparison was significant in the HP-LES group $(P$-values $>0.1)$. The HP-CTRL and HP-LES groups were significantly different in their performance within the first and last days of SAL injections $(P$ values $<0.01$ ).

For better understanding of the results, an ANOVA (with the lesion group as a between-subject variable and the drug condition as a within-subject variable) was also performed on the data separated by the rule (as presented in the insets in Fig. 4B,C). For the location-in-place rule, there was a significant effect of the lesion group $\left(F_{(1,10)}=15.9, P<0.01\right)$. The drug-condition variable failed to reach significance $\left(F_{(1,10)}=4.5, P=0.06\right)$ and there was no interaction between the two variables $\left(F_{(1,10)}=0.05\right.$, $P>0.5)$. For the object-in-place rule, however, there were significant effects of the lesion group $\left(F_{(1,10)}=76.0, P<0.0001\right)$, the drug condition $\left(F_{(1,10)}=51.3, P<0.0001\right)$, and the interaction between the two variables $\left(F_{(1,10)}=37.4, P=0.0001\right)$. Further comparisons between conditions revealed that the HP-CTRL group was significantly impaired in performance when MUS was injected in the MPFC $(P<0.001$; paired $t$-test $)$, whereas no significance between SAL and MUS conditions was found in the HP-LES group $(P>0.1)$. The performance between the HP-LES and HP-CTRL groups was significantly different when SAL was injected in the mPFC $(P<0.0001 ; t$-test $)$, but failed to reach significance when MUS was injected $(P=0.06)$.

Overall, these results strongly demonstrate that the animals need both the hippocampus and mPFC to perform normally in the current task, and the malfunctioning of the mPFC is more disruptive in normal animals for processing object-place paired association in comparison to location-place paired association.

\section{Response bias}

During the training and testing periods in the current task, rats are required to overcome any response bias (i.e., remembering particular turning directions) for successful performance. To quantify the response bias, a response bias index was calculated as follows: (\#Left Choice - \#Right Choice)/(\#Left Choice + \#Right Choice), where \#Left Choice or \#Right Choice denotes the number of left or right choices made in the task. The response bias index of 1 thus indicates a perfect response bias (i.e., perseverative turning to only one side) and 0 represents no response bias (i.e., equally distributed left and right responses). 
A.

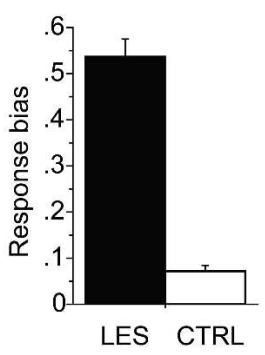

C.

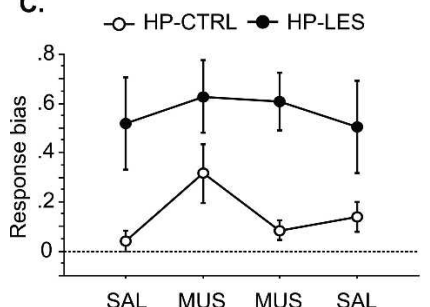

B.
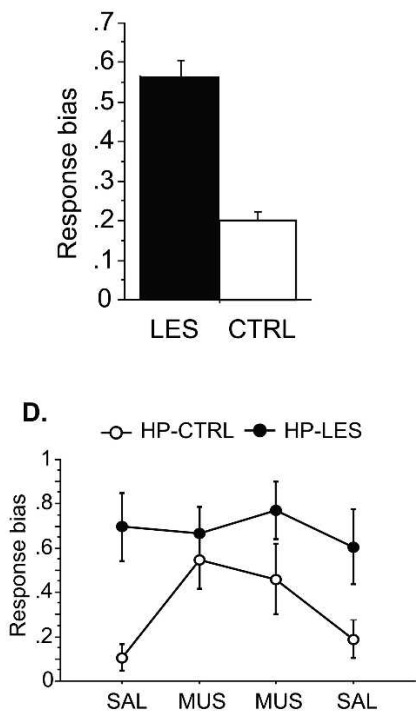

Figure 5. Egocentric response bias in the hippocampal-lesioned rats. (A) Response bias index $(0=$ no response bias; $1=$ perfect response bias $)$ calculated for location-in-place arms and averaged across the $10 \mathrm{~d}$ of post-surgical testing period for each group is shown. LES, HP-LES group; CTRL, HP-CTRL group. (B) Response bias index for object-in-place arms for the $10 \mathrm{~d}$ of post-surgical testing period for each group. (C) Response bias index for location-in-place arms during the $4 \mathrm{~d}$ of drug-injection period. $(D)$ Response bias index for object-in-place arms during the $4 \mathrm{~d}$ of drug-injection period. HP-CTRL, control lesion group; HP-LES, neurotoxic lesion group. All graphs show mean \pm SEM.

On average, during $10 \mathrm{~d}$ of post-surgical testing without drug injections, the HP-LES group exhibited marked response bias in both location-in-place arms (Fig. 5A) and object-in-place arms (Fig. 5B), compared to the HP-CTRL group. There were significant effects of the lesion group both in location-place pairedassociate trials $\left(F_{(1,128)}=125.9, P<0.0001\right)$ and object-place paired-associate trials $\left(F_{(1,128)}=63.3, P<0.0001\right)$. When SAL or MUS was injected after $10 \mathrm{~d}$ of testing, the response bias of the HP-LES group remained high regardless of the drug injection conditions (Fig. 5C,D). However, the rats in the HP-CTRL group showed increased response bias in location-in-place arms (Fig. 5C) and in object-in-place arms (Fig. 5D) only when their performance was impaired in those arms after MUS injections (cf. Fig. 5C,D with Fig. 4B,C). In location-in-place arms (Fig. 5C), there was a significant effect of the lesion group $\left(F_{(1,10)}=8.5\right.$, $P<0.05$; ANOVA with repeated measures), but no significant effect was found either for the drug-injection condition $\left.{ }_{(3,30)}=1.9, P=0.1\right)$ or for the interaction between the lesion group and drug-injection condition $\left(F_{(3,30)}=0.4, P=0.7\right)$. In object-in-place arms (Fig. 5D), a significant effect of the lesion group $\left(F_{(1,10)}=6.7, P<0.05\right.$; ANOVA with repeated measures) was found. There was a trend of the effect of the drug-injection condition $\left(F_{(3,30)}=2.9, P=0.05\right)$, but no significant interaction was found between the lesion group and the drug-injection condition $\left(F_{(3,30)}=1.3, P=0.3\right)$. When the response bias was examined for each object-in-place arm in the HP-LES group and HPCTRL group with MUS inactivations (a similar response bias analysis for each location-in-place arm is irrelevant since each arm needs to be associated with either left or right food well in location-in-place conditions), the response bias was randomly associated with one of the object-in-place arms and no particular arm caused more response bias (paired $t$-test, $P$-values $>0.1$ ). These results suggest that the interaction between the mPFC and

hippocampus is crucial for remembering spatial paired associates in the environment according to relevant rules and the animals may be left with a simple habitual response system (e.g., response bias) with the failure on either side of the interaction between the hippocampus and mPFC.

\section{Latency to object choice}

In each trial, the latency from entering the arm to displacing an object in the choice platform was measured. During the postsurgical testing period of $10 \mathrm{~d}$, the HP-LES group was faster than the HP-CTRL group in running down an arm and making a choice (Fig. 6A). An ANOVA on the latency averaged across those $10 \mathrm{~d}$ showed a significant difference between the two lesion groups $\left(F_{(1,128)}=8.8, P<0.01\right)$. Injecting MUS in the mPFC also resulted in faster choices in both the HP-LES and HP-CTRL groups (Fig. 6B). An ANOVA with repeated measures showed a significant effect of the lesion group $\left(F_{(1,10)}=8.1, P<0.05\right)$ and a significant effect of the drug condition $\left(F_{(1,10)}=7.7, P<0.05\right)$, but no significant effect of the interaction between the two variables $\left(F_{(1,10)}=1.0, P>0.1\right)$.

\section{Simple object discrimination task}

One possibility that might underlie the performance deficits described above is that the neurotoxic damage in the hippocampus and/or the temporary inactivation of the mPFC might have caused sensory and/or motor deficits that impaired object discrimination in general. For example, the lesioned and/or MUSinjected rats might have had difficulties in identifying individual objects (e.g., due to impairment in vision, etc.). This possibility was tested by training the same animals with a simple object discrimination task (Fig. 7A) after the $14 \mathrm{~d}$ of post-surgical testing period. In this task, it was unnecessary to associate different rules for reward with different arms because only one new arm (arm 4 in the middle of the maze) was used, associated with only one rule; that is, the rat needed to choose one of two toy objects (new toy objects, toy kid and oil can, that had not been used in the original task) regardless of their locations in the choice platform and the toy kid was always rewarded.

The rats in both lesion groups learned the task quickly within 2-3 d on average (Fig. 7B). Comparing the number of trials to criterion ( $\geq 75 \%$ for two consecutive days) with an ANOVA revealed no significant difference between the HP-CTRL and HP-LES groups $\left(F_{(1,10)}=0.9, P=0.35\right)$. When SAL or MUS was injected after the rats learned the task, there was no impairment with either SAL or MUS in either lesion group (Fig. 7C). On the basis of an ANOVA with repeated measures (the drug-injection conditions as a within-subject variable and the lesion group as a
A.

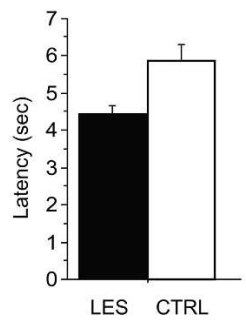

B.

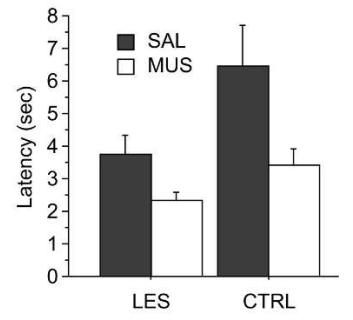

Figure 6. Latency measured in seconds (sec) from arm-entering to object-choice. (A) Average latency measured across $10 \mathrm{~d}$ of post-surgical testing without drug injection in each lesion group (CTRL, control lesion group; LES, neurotoxic lesion group). (B) Average latency measured in each group during the $4 \mathrm{~d}$ of drug injection period in MPFC with SAL or MUS. Two days of SAL or MUS data were averaged. All graphs show mean \pm SEM. 
A.

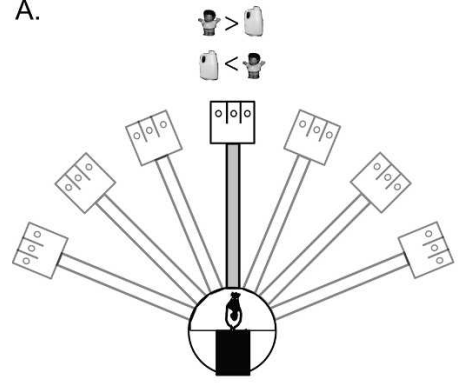

B.

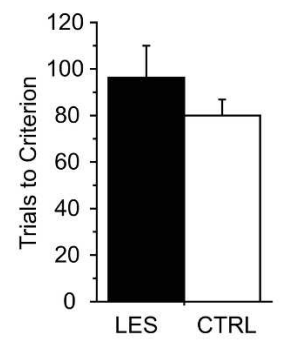

C.

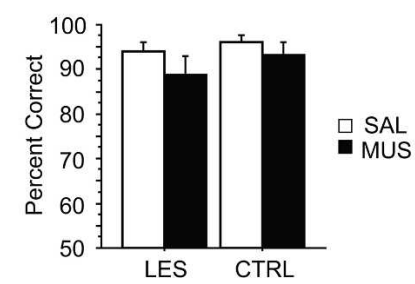

D.

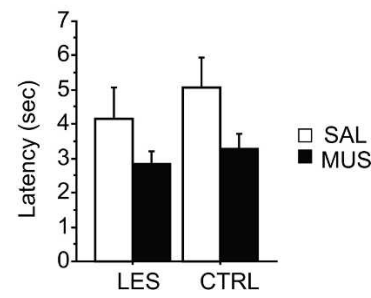

Figure 7. Simple object-discrimination task. (A) Illustration of the object discrimination task, using only one arm (arm 4) of the maze (other arms unused are colored in light gray). Two novel objects (a toy kid and an oil can) were used and the rule was to choose the toy kid always regardless of its location in the choice platform. $(B)$ The number of trials required to reach the criterion performance level in each group (CTRL, control lesion group; LES, neurotoxic lesion group). (C) Performance in the same task with SAL or MUS injections in MPFC. Data from the $2 \mathrm{~d}$ of SAL or MUS injection conditions were combined. $(D)$ Latency to choosing an object in the task with SAL or MUS injections (2 d of SAL or MUS injections averaged). All graphs show mean \pm SEM.

between-subject variable), there was no effect of the lesion group $\left(F_{(1,10)}=0.9, P=0.4\right)$, drug-injection condition $\left(F_{(1,10)}=4.4\right.$, $P=0.06)$, or interaction between the two variables $\left(F_{(1,10)}=0.4\right.$, $P=0.6)$. Further supporting the equivalent performance, although there was the effect of drug $\left(F_{(1,10)}=9.7, P=0.01\right)$ (Fig. 7D), there was no significant difference in choice latency between the two groups in the simple object discrimination task ( $P$-values $>0.1$ for the effects of the lesion group and the interaction between the lesion group and drug). It is concluded, therefore, that the rats with hippocampal lesions and/or MUS injections in the mPFC in this study were able to normally discriminate different objects.

\section{Discussion}

In the current study, rats were trained to choose a correct object (object-place paired association) or a correct food well location (location-place paired association) depending on the place (i.e., arm) in which the choice needed to be made. The selective removal of the hippocampus resulted in marked impairment in performance in both object-in-place and location-in-place arms. Inactivating the mPFC in the animals with intact hippocampi, however, produced profound deficits only in the object-in-place arms but did so minimally in the location-in-place arms. The severe deficits observed in the hippocampal-lesioned and mPFCinactivated rats, however, disappeared when the task required only a simple object discrimination in a single arm. The current study is important since it reveals the relative contributions of the hippocampus and the MPFC (previously shown by separate studies targeting each structure in isolation) within a single behavioral paradigm using a within-subject design. With respect to the role of the hippocampus, our results confirm the previous findings (Gilbert and Kesner 2002, 2004) that the hippocampus is necessary in paired-associate learning when space is a critical variable. As for the mPFC, however, it is only involved in the object-place paired-associate learning, but not in the locationplace paired-associate learning in our study. Both the hippocampus and mPFC are not necessary for learning a simple object discrimination.

The development of the current behavioral paradigm was motivated by the need for a task that would maximally recruit the brain areas such as the hippocampus and prefrontal cortex that are critical for associating objects with discrete locations in space. Although the design of the current task was inspired by the Go/No-Go task originally developed by Kesner and colleagues (Gilbert and Kesner 2002, 2003; Kesner and Ragozzino 2003; Gilbert and Kesner 2004), the following differences are noteworthy between the two tasks. Firstly, different rules (object-in-place and location-in-place) compete with each other in the current task, whereas only a single rule (i.e., object-in-place) was valid in the original Go/No-Go task. The current task thus may create a condition in which the prefrontal cortical involvement can be tested for processing rules as well as selecting/inhibiting responses according to the rules. Secondly, the Go/No-Go paradigm is not ideal for an electrophysiological recording experiment mainly because the sampling for neural firing patterns in critical locations can only occur in Go trials, but not in No-Go trials. In contrast, rats are required to travel to the choice platform in every trial in the current task, thus making the paradigm readily available for electrophysiological studies in the future. Finally, the amount of ambiguity among the events is greater in the current task since the same objects appear repeatedly across all trials, whereas only one object is presented in a given trial in the Go/No-Go task. It is noteworthy that rats with hippocampal lesions recover their performance after an initial impairment in the original Go/No-Go task when they were retested in the task after surgery (Gilbert and Kesner 2004). In contrast, in our task, the HP-LES group showed no improvement throughout the entire post-surgical testing period, and this may stem from the greater need for forming/retrieving discrete object-place representations using overlapping items and locations in space in the current task. Recent experimental literature and computational models have emphasized the importance of the hippocampus in forming/retrieving orthogonal representations of ambiguous events and their associated contexts (Marr 1971; O'Reilly and McClelland 1994; Treves and Rolls 1994; Gilbert et al. 1998; Tanila 1999; Vazdarjanova and Guzowski 2004; Leutgeb et al. 2007; McHugh et al. 2007). The current task may be used as a powerful experimental paradigm for testing the functional significance of the hippocampal subfields in disambiguating similar events involving object-place associations.

It would be useful to speculate on the cognitive processes that may be critical as the rats make correct choices in the current paradigm. First of all, "spatial mapping" is necessary. That is, as the animal exits the start box and enters a particular arm in the maze, the rat is required to map its location in the maze (or in the testing room). It is likely that the hippocampus is critical at this stage. The principal neurons ("place cells") in the hippocampus fire in a location-specific fashion (O'Keefe and Dostrovsky 1971; Muller et al. 1987), and a leading hypothesis states that mapping the animal's location is critically dependent on the place cells in the hippocampus (O'Keefe and Nadel 1978). In the current study, the HP-LES group was impaired in performing both object-inplace and location-in-place trials. Both types of paired-associate trials require the rats to first identify the place information (i.e., arm location) correctly. Therefore, it is possible that the rats with hippocampal lesions were unable to perform the current task due to the lack of accurate spatial mapping. The second stage would be "rule retrieval" (i.e., object-place association vs. location- 
place association) on the basis of the place information from the spatial mapping stage. The prefrontal cortex is likely to play a significant role at this stage, considering its involvement in rule learning, suggested in numerous studies (Otto and Eichenbaum 1992; Winocur and Eskes 1998; White and Wise 1999; Asaad et al. 2000; Hoshi et al. 2000; Wallis et al. 2001). Finally, as an appropriate rule is identified in a given choice platform (e.g., objectin-place rule in arm 5), the rat is required to remember a "specific paired associate" (e.g., Spider-Man) that would result in a reward. It is conceivable that these cognitive stages need to be successfully fulfilled to result in a correct choice response in our task.

In our task, there were differences in performance between object-in-place and location-in-place arms during the postsurgical testing period and this may need further discussion. Specifically, although the HP-LES group showed poor performance during $10 \mathrm{~d}$ of post-surgical testing in both types of pairedassociation trials, more severe and sustained deficits were observed in object-in-place arms than in location-in-place arms. A similar trend was also observed when the mPFC was inactivated in the HP-CTRL group in which the inactivation severely affected performance only in object-in-place arms, but not in locationin-place arms. These results suggest that object-in-place trials in the current task demand a full commitment of the hippocampus and $\mathrm{mPFC}$, whereas that may not be the case in location-in-place trials. In a pilot study in our laboratory, hippocampal-lesioned rats never learned the object-in-place paired-associate problems even when the task did not involve location-in-place trials (data not shown). This suggests that the differences in performance between the two trial types may not stem from the interference between different trial types or rules.

There are several possibilities that may explain the abovementioned differences in performance. Most of all, it may depend on whether an alternative strategy is possible. Specifically, when tested after surgery, the HP-LES group may have changed their strategy in the location-in-place arms. It is possible that the rats associated the spatial information of arm 3 (one of the location-in-place arms), for example, with the right food well in the choice platform before they underwent neurotoxic surgery. After surgery, however, as they suffered from poor performance during the earlier phase of testing (Fig. 3B), they might have adopted an egocentric response strategy (Packard and McGaugh 1996; DeCoteau and Kesner 2000; Hartley et al. 2003) by associating specific turning directions leading to reward locations in the location-inplace arms. Since either left or right turning response would lead to a correct food well in a given location-in-place arm, this strategy might have been adopted by the mPFC-inactivated rats as an alternative strategy for the location-place paired-associate learning. This alternative strategy, however, still requires the rats to know the arm information with which a discrete turning response can be associated. The arm information in this case may be provided in the form of directional signal since each arm entrance maintains a unique angular relationship with the start box location. The existence of the head direction system outside the hippocampus in rats (Taube et al. 1990; Taube 1995) makes this alternative strategy feasible in the absence of the hippocampus. The response bias analysis (Fig. 5) demonstrates how readily rats became dependent on an egocentric strategy as the performance decreased. Similarly, by the time the rats in the HP-CTRL group were tested with MUS injections in the mPFC (days 12-13), the performance of those rats in the location-in-place arms might have been controlled by the egocentric response-based system (e.g., striatal-based learning) (Cook and Kesner 1988; Packard and McGaugh 1996; DeCoteau and Kesner 2000; Hartley et al. 2003). Then, the reason why the hippocampal lesions and mPFC inactivations produced more profound deficits in object-place paired associations than in location-place paired associations may be that such an egocentric strategy could not be used to make a correct choice in object-in-place arms because both left and right body turns could be associated with a correct object in each object-in-place arm.

Secondly, it may be that the amount of conflict or ambiguity that needs to be resolved at the time of choice behavior is greater in object-in-place trials than in location-in-place trials. Specifically, the number of possible responses that can be made at the choice platform was greater in the object-in-place arms than in the location-in-place arms. This is because both left and right food wells could be associated with a correct object in each object-in-place arm, whereas only one food well was associated with reward in each location-in-place arm. The complexity of response selection should be thus greater in the object-in-place condition in the current task, and the literature suggests that the prefrontal cortex is critically involved in making a correct response when conflicting responses compete with each other (Winocur and Eskes 1998; Haddon and Killcross 2006). For example, Haddon and Killcross (2006), using also a biconditional association task, showed that the PFC is critical when conflicting responses need to be resolved by a contextual cue. This line of reasoning may be extended to the object-place pairedassociation condition in our task since conflicting responses (left and right food well choices that are both relevant in both objectin-place arms) should be clarified by the spatial context associated with a given arm.

With the inactivation of the mPFC in particular, the difference in performance between object-in-place and location-inplace trials may also be explained by the lack of flexibility in switching between object-in-place and response-in-place rules. The mPFC has been known for its involvement in rule switching or task switching (Ragozzino et al. 1999; Porter et al. 2000; Rich and Shapiro 2007). As a result of the mPFC inactivation, the rats may have used the location-in-place rule in object-in-place trials. A bias in an opposite direction (i.e., using predominantly the object-in-place rule even in location-in-place trials) was never observed in the current study and this may be due to the aforementioned differences between object-in-place and location-inplace trials in terms of the level of complexity and ambiguity. That is, the rats with the MPFC inactivations may have developed a bias for using the less complicated rule or strategy (i.e., location-in-place) predominantly throughout the task.

Some qualitative differences in behavior observed in relation to the latency data (Fig. 6) are worth mentioning. The animals with hippocampal lesions and/or inactivations in the mPFC often make quicker choices than controls. The rats in the HPCTRL group without MUS injection, for example, often paused in front of the objects when they reached the choice platform, which increased their latency. Sometimes they even returned to the center platform and showed rearing behavior seemingly to better observe the cues around the maze before they reapproached the choice platform. The animals in the HP-LES group or those in the HP-CTRL group with MUS injections in the mPFC, however, rarely showed such an inhibitory behavior and tended to make immediate choices once they reached the choice platform. The results match the descriptions provided in earlier literature to explain similar behaviors of rats in terms of vicarious trial-and-error (Tolman 1938, 1939; Hu and Amsel 1995).

A striking finding in the current study is that, in the objectin-place arms, inactivating the MPFC in the HP-CTRL group resulted in almost identical effects on performance (i.e., chance level) seen in the HP-LES group (Fig. 4C). The results thus demonstrate, using a single behavioral paradigm, the roles of the hippocampus and $\mathrm{mPFC}$ that have been shown in separate studies (Gilbert and Kesner 2002, 2003; Kesner and Ragozzino 2003; Gilbert and Kesner 2004). Barker et al. (2007) also tested mPFC- 
lesioned rats between similar object-in-place conditions and showed that the lesioned animals had difficulties in detecting differences between those conditions. These findings collectively suggest that the hippocampus and mPFC may work as a unified functional network when individual items (e.g., objects) and their spatial locations need to be associated for generating eventspecific behavioral responses. Supporting evidence can be found in anatomical literature (Lavenex and Amaral 2000; Witter and Amaral 2004; Munoz and Insausti 2005; Furtak et al. 2007; Kerr et al. 2007) showing relatively segregated pathways for spatial and nonspatial sensory inputs converging in the hippocampus, the former mediated by the postrhinal cortex (or parahippocampal cortex in primates)-to-medial entorhinal cortex and the latter transferred via the perirhinal cortex-to-lateral entorhinal cortex. The hippocampus, therefore, is positioned in an ideal place in the information-processing stream for object-place paired association (as well as for location-place paired association). Physiological correlates for both spatial and nonspatial variables in the entorhinal cortex also support such a conjecture (Suzuki et al. 1997; Fyhn et al. 2004; Hafting et al. 2005; Hargreaves et al. 2005). It is possible that the PFC, via its direct efferents to the entorhinal cortex (Jay and Witter 1991; Carmichael and Price 1995; Kolb and Cioe 2004), may influence or bias how the object and place information is fed into the hippocampal network.

\section{Acknowledgments}

We thank Dr. John Freeman and Dr. Raymond Kesner for helpful comments on the manuscript. We also thank Crystal Meyer for assistance in behavioral data collection and Jangjin Kim for assisting data analysis. This study was supported by grant R01 MH079971.

\section{References}

Angeli, S.J., Murray, E.A., and Mishkin, M. 1993. Hippocampectomized monkeys can remember one place but not two. Neuropsychologia 31: 1021-1030.

Asaad, W.F., Rainer, G., and Miller, E.K. 2000. Task-specific neural activity in the primate prefrontal cortex. J. Neurophysiol. 84: 451-459.

Bachevalier, J. and Nemanic, S. 2008. Memory for spatial location and object-place associations are differently processed by the hippocampal formation, parahippocampal areas TH/TF and perirhinal cortex. Hippocampus 18: 64-80.

Barker, G.R.I., Bird, F., Alexander, V., and Warburton, E.C. 2007. Recognition memory for objects, place, and temporal order: A disconnection analysis of the role of the medial prefrontal cortex and perirhinal cortex. J. Neurosci. 27: 2948-2957.

Cahusac, P.M., Miyashita, Y., and Rolls, E.T. 1989. Responses of hippocampal formation neurons in the monkey related to delayed spatial response and object-place memory tasks. Behav. Brain Res. 33: $229-240$.

Carmichael, S.T. and Price, J.L. 1995. Limbic connections of the orbital and medial prefrontal cortex in macaque monkeys. J. Comp. Neurol. 363: 615-641.

Cook, D. and Kesner, R.P. 1988. Caudate nucleus and memory for egocentric localization. Behav. Neural Biol. 49: 332-343.

DeCoteau, W.E. and Kesner, R.P. 2000. A double dissociation between the rat hippocampus and medial caudoputamen in processing two forms of knowledge. Behav. Neurosci. 114: 1096-1108.

Doeller, C.F., Opitz, B., Krick, C.M., Mecklinger, A., and Reith, W. 2005. Prefrontal-hippocampal dynamics involved in learning regularities across episodes. Cereb. Cortex 15: 1123-1133.

Eacott, M.J. and Norman, G. 2004. Integrated memory for object, place, and context in rats: A possible model of episodic-like memory? $J$. Neurosci. 24: 1948-1953.

Floresco, S.B., Seamans, J.K., and Phillips, A.G. 1997. Selective roles for hippocampal, prefrontal cortical, and ventral striatal circuits in radial-arm maze tasks with or without a delay. J. Neurosci. 17: $1880-1890$.

Furtak, S.C., Wei, S.M., Agster, K.L., and Burwell, R.D. 2007. Functional neuroanatomy of the parahippocampal region in the rat: The perirhinal and postrhinal cortices. Hippocampus 17: 709-722.

Fyhn, M., Molden, S., Witter, M.P., Moser, E.I., and Moser, M.B. 2004. Spatial representation in the entorhinal cortex. Science
305: $1258-1264$.

Gaffan, D. 1998. Idiothetic input into object-place configuration as the contribution to memory of the monkey and human hippocampus: A review. Exp. Brain Res. 123: 201-209.

Gilbert, P.E. and Kesner, R.P. 2002. Role of the rodent hippocampus in paired-associate learning involving associations between a stimulus and a spatial location. Behav. Neurosci. 116: 63-71.

Gilbert, P.E. and Kesner, R.P. 2003. Localization of function within the dorsal hippocampus: The role of the CA3 subregion in paired-associate learning. Behav. Neurosci. 117: 1385-1394.

Gilbert, P.E. and Kesner, R.P. 2004. Memory for objects and their locations: The role of the hippocampus in retention of object-place associations. Neurobiol. Learn. Mem. 81: 39-45.

Gilbert, P.E., Kesner, R.P., and DeCoteau, W.E. 1998. Memory for spatial location: Role of the hippocampus in mediating spatial pattern separation. J. Neurosci. 18: 804-810.

Gilbert, P.E., Kesner, R.P., and Lee, I. 2001. Dissociating hippocampal subregions: Double dissociation between dentate gyrus and CA1. Hippocampus 11: 626-636.

Granon, S. and Poucet, B. 1995. Medial prefrontal lesions in the rat and spatial navigation: Evidence for impaired planning. Behav. Neurosci. 109: 474-484

Granon, S., Vidal, C., Thinus-Blanc, C., Changeux, J.P., and Poucet, B. 1994. Working memory, response selection, and effortful processing in rats with medial prefrontal lesions. Behav. Neurosci. 108: 883-891.

Granon, S., Save, E., Buhot, M.C., and Poucet, B. 1996. Effortful information processing in a spontaneous spatial situation by rats with medial prefrontal lesions. Behav. Brain Res. 78: 147-154.

Haddon, J.E. and Killcross, S. 2006. Prefrontal cortex lesions disrupt the contextual control of response conflict. J. Neurosci. 26: 2933-2940.

Hafting, T., Fyhn, M., Molden, S., Moser, M.B., and Moser, E.I. 2005. Microstructure of a spatial map in the entorhinal cortex. Nature 436: 801-806.

Hargreaves, E.L., Rao, G., Lee, I., and Knierim, J.J. 2005. Major dissociation between medial and lateral entorhinal input to dorsal hippocampus. Science 308: 1792-1794.

Hartley, T., Maguire, E.A., Spiers, H.J., and Burgess, N. 2003. The well-worn route and the path less traveled: Distinct neural bases of route following and wayfinding in humans. Neuron 37: 877-888.

Hoshi, E., Shima, K., and Tanji, J. 1998. Task-dependent selectivity of movement-related neuronal activity in the primate prefrontal cortex. J. Neurophysiol. 80: 3392-3397.

Hoshi, E., Shima, K., and Tanji, J. 2000. Neuronal activity in the primate prefrontal cortex in the process of motor selection based on two behavioral rules. J. Neurophysiol. 83: 2355-2373.

$\mathrm{Hu}, \mathrm{D}$. and Amsel, A. 1995. A simple test of the vicarious trial-and-error hypothesis of hippocampal function. Proc. Natl. Acad. Sci. 92: 5506-5509.

Hunsaker, M.R., Thorup, J.A., Welch, T., and Kesner, R.P. 2006. The role of CA3 and CA1 in the acquisition of an object-trace-place paired-associate task. Behav. Neurosci. 120: 1252-1256.

Hyman, J.M., Zilli, E.A., Paley, A.M., and Hasselmo, M.E. 2005. Medial prefrontal cortex cells show dynamic modulation with the hippocampal theta rhythm dependent on behavior. Hippocampus 15: $739-749$.

Jay, T.M. and Witter, M.P. 1991. Distribution of hippocampal CA1 and subicular efferents in the prefrontal cortex of the rat studied by means of anterograde transport of Phaseolus vulgaris-leucoagglutinin. J. Comp. Neurol. 313: 574-586.

Jo, Y.S., Park, E.H., Kim, I.H., Park, S.K., Kim, H., Kim, H.T., and Choi, J.-S. 2007. The medial prefrontal cortex is involved in spatial memory retrieval under partial-cue conditions. J. Neurosci. 27: 13567-13578.

Johnston, K., Levin, H.M., Koval, M.J., and Everling, S. 2007. Top-down control-signal dynamics in anterior cingulate and prefrontal cortex neurons following task switching. Neuron 53: 453-462.

Jones, M.W. and Wilson, M.A. 2005. Theta rhythms coordinate hippocampal-prefrontal interactions in a spatial memory task. PLoS Biol. 3: e402. doi: 10.1371/journal.pbio.0030402.

Kesner, R.P. and Ragozzino, M.E. 2003. The role of the prefrontal cortex in object-place learning: A test of the attribute specificity model. Behav. Brain Res. 146: 159-165.

Kolb, B. and Cioe, J. 2004. Organization and plasticity of the prefrontal cortex of the rat. In Prefrontal cortex: From synaptic plasticity to cognition (ed. S. Otani), pp. 1-32. Kluwer Academic Publishers, Norwell, MA.

Kerr, K.M., Agster, K.L., Furtak, S.C., and Burwell, R.D. 2007. Functional neuroanatomy of the parahippocampal region: The lateral and medial entorhinal areas. Hippocampus 17: 697-708.

Kyd, R.J. and Bilkey, D.K. 2005. Hippocampal place cells show increased sensitivity to changes in the local environment following prefrontal cortex lesions. Cereb. Cortex 15: 720-731. 
Lavenex, P. and Amaral, D.G. 2000. Hippocampal-neocortical interaction: A hierarchy of associativity. Hippocampus 10: 420-430.

Lee, I. and Kesner, R.P. 2003a. Differential roles of dorsal hippocampal subregions in spatial working memory with short versus intermediate delay. Behav. Neurosci. 117: 1044-1053.

Lee, I. and Kesner, R.P. 2003b. Time-dependent relationship between the dorsal hippocampus and the prefrontal cortex in spatial memory. J. Neurosci. 23: 1517-1523.

Lee, I. and Kesner, R.P. 2004. Differential contributions of dorsal hippocampal subregions to memory acquisition and retrieval in contextual fear-conditioning. Hippocampus 14: 301-310.

Lee, I., Hunsaker, M.R., and Kesner, R.P. 2005. The role of hippocampal subregions in detecting spatial novelty. Behav. Neurosci.

119: $145-153$.

Leutgeb, J.K., Leutgeb, S., Moser, M.-B., and Moser, E.I. 2007. Pattern separation in the dentate gyrus and CA3 of the hippocampus. Science 315: $961-966$.

Malkova, L. and Mishkin, M. 2003. One-trial memory for object-place associations after separate lesions of hippocampus and posterior parahippocampal region in the monkey. J. Neurosci. 23: 1956-1965.

Mansouri, F.A., Buckley, M.J., and Tanaka, K. 2007. Mnemonic function of the dorsolateral prefrontal cortex in conflict-induced behavioral adjustment. Science 318: 987-990.

Marr, D. 1971. Simple memory: A theory for archicortex. Philos. Trans. R. Soc. Lond. B Biol. Sci. 262: 23-81.

McHugh, T.J., Jones, M.W., Quinn, J.J., Balthasar, N., Coppari, R., Elmquist, J.K., Lowell, B.B., Fanselow, M.S., Wilson, M.A., and Tonegawa, S. 2007. Dentate gyrus NMDA receptors mediate rapid pattern separation in the hippocampal network. Science 317: 94-99.

McNaughton, B.L. and Morris, R.G.M. 1987. Hippocampal synaptic enhancement and information storage within a distributed memory system. Trends Neurosci. 10: 408-415.

Milham, M.P., Banich, M.T., Claus, E.D., and Cohen, N.J. 2003. Practice-related effects demonstrate complementary roles of anterior cingulate and prefrontal cortices in attentional control. Neuroimage 18: $483-493$.

Milner, B., Johnsrude, I., and Crane, J. 1997. Right medial temporal-lobe contribution to object-location memory. Philos. Trans. R. Soc. Lond. B Biol. Sci. 352: 1469-1474.

Morris, R.G., Garrud, P., Rawlins, J.N., and O'Keefe, J. 1982. Place navigation impaired in rats with hippocampal lesions. Nature 297: 681-683.

Muller, R.U., Kubie, J.L., and Ranck Jr., J.B. 1987. Spatial firing patterns of hippocampal complex-spike cells in a fixed environment. $J$. Neurosci. 7: 1935-1950.

Munoz, M. and Insausti, R. 2005. Cortical efferents of the entorhinal cortex and the adjacent parahippocampal region in the monkey (Macaca fascicularis). Eur. J. Neurosci. 22: 1368-1388.

O'Keefe, J. and Dostrovsky, J. 1971. The hippocampus as a spatial map: Preliminary evidence from unit activity in the freely-moving rat. Brain Res. 34: 171-175.

O'Keefe, J. and Nadel, L. 1978. The hippocampus as a cognitive map. Clarendon Press, Oxford.

O’Reilly, R.C. and McClelland, J.L. 1994. Hippocampal conjunctive encoding, storage, and recall: Avoiding a trade-off. Hippocampus 4: $661-682$.

Otto, T. and Eichenbaum, H. 1992. Complementary roles of the orbital prefrontal cortex and the perirhinal-entorhinal cortices in an odor-guided delayed-nonmatching-to-sample task. Behav. Neurosci. 106: $762-775$.

Packard, M.G. and McGaugh, J.L. 1996. Inactivation of hippocampus or caudate nucleus with lidocaine differentially affects expression of place and response learning. Neurobiol. Learn. Mem. 65: 65-72.

Parkinson, J.K., Murray, E.A., and Mishkin, M. 1988. A selective mnemonic role for the hippocampus in monkeys: Memory for the location of objects. J. Neurosci. 8: 4159-4167.

Paxinos, G. and Watson, C. 1986. The rat brain in stereotaxic coordinates, 2d ed. Academic Press, San Diego, CA.

Porter, M.C., Burk, J.A., and Mair, R.G. 2000. A comparison of the effects of hippocampal or prefrontal cortical lesions on three versions of delayed non-matching-to-sample based on positional or spatial cues. Behav. Brain Res. 109: 69-81.

Poucet, B., Lenck-Santini, P.P., Hok, V., Save, E., Banquet, J.P., Gaussier, P., and Muller, R.U. 2004. Spatial navigation and hippocampal place cell firing: The problem of goal encoding. Rev. Neurosci. 15: 89-107.

Ragozzino, M.E., Adams, S., and Kesner, R.P. 1998. Differential involvement of the dorsal anterior cingulate and prelimbic-infralimbic areas of the rodent prefrontal cortex in spatial working memory. Behav. Neurosci. 112: 293-303.

Ragozzino, M.E., Detrick, S., and Kesner, R.P. 1999. Involvement of the prelimbic-infralimbic areas of the rodent prefrontal cortex in behavioral flexibility for place and response learning. J. Neurosci. 19: $4585-4594$.

Ragozzino, M.E., Detrick, S., and Kesner, R.P. 2002. The effects of prelimbic and infralimbic lesions on working memory for visual objects in rats. Neurobiol. Learn. Mem. 77: 29-43.

Ragozzino, M.E., Kim, J., Hassert, D., Minniti, N., and Kiang, C. 2003. The contribution of the rat prelimbic-infralimbic areas to different forms of task switching. Behav. Neurosci. 117: 1054-1065.

Rich, E.L. and Shapiro, M.L. 2007. Prelimbic/infralimbic inactivation impairs memory for multiple task switches, but not flexible selection of familiar tasks. J. Neurosci. 27: 4747-4755.

Rolls, E.T. and Kesner, R.P. 2006. A computational theory of hippocampal function, and empirical tests of the theory. Prog. Neurobiol. 79: 1-48.

Rolls, E.T., Miyashita, Y., Cahusac, P.M., Kesner, R.P., Niki, H., Feigenbaum, J.D., and Bach, L. 1989. Hippocampal neurons in the monkey with activity related to the place in which a stimulus is shown. J. Neurosci. 9: 1835-1845.

Rolls, E.T., Xiang, J., and Franco, L. 2005. Object, space, and object-space representations in the primate hippocampus. $J$. Neurophysiol. 94: 833-844.

Suzuki, W.A., Miller, E.K., and Desimone, R. 1997. Object and place memory in the macaque entorhinal cortex. J. Neurophysiol. 78: $1062-1081$.

Sziklas, V., Petrides, M., and Leri, F. 1996. The effects of lesions to the mammillary region and the hippocampus on conditional associative learning by rats. Eur. J. Neurosci. 8: 106-115.

Sziklas, V., Lebel, S., and Petrides, M. 1998. Conditional associative learning and the hippocampal system. Hippocampus 8: 131-137.

Tanila, H. 1999. Hippocampal place cells can develop distinct representations of two visually identical environments. Hippocampus 9: $235-246$.

Taube, J.S. 1995. Head direction cells recorded in the anterior thalamic nuclei of freely moving rats. J. Neurosci. 15: 70-86.

Taube, J.S., Muller, R.U., and Ranck Jr., J.B. 1990. Head-direction cells recorded from the postsubiculum in freely moving rats. I. Description and quantitative analysis. J. Neurosci. 10: $420-435$.

Thierry, A.-M., Gioanni, Y., Degenetais, E., and Glowinski, J. 2000. Hippocampo-prefrontal cortex pathway: Anatomical and electrophysiological characteristics. Hippocampus 10: 411-419.

Tolman, E.C. 1938. The determiners of behavior at a choice point. Psychol. Rev. 46: 318-336.

Tolman, E.C. 1939. Prediction of vacarious trial and error by means of the schematic sowbug. Psychol. Rev. 46: 318-336.

Treves, A. and Rolls, E.T. 1994. Computational analysis of the role of the hippocampus in memory. Hippocampus 4: 374-391.

Vargha-Khadem, F., Gadian, D.G., Watkins, K.E., Connelly, A., Van Paesschen, W., and Mishkin, M. 1997. Differential effects of early hippocampal pathology on episodic and semantic memory. Science 277: $376-380$.

Vazdarjanova, A. and Guzowski, J.F. 2004. Differences in hippocampal neuronal population responses to modifications of an environmental context: Evidence for distinct, yet complementary, functions of CA3 and CA1 ensembles. J. Neurosci. 24: 6489-6496.

Wallis, J.D., Anderson, K.C., and Miller, E.K. 2001. Single neurons in prefrontal cortex encode abstract rules. Nature 411: 953-956.

Wang, G. and Cai, J. 2006. Disconnection of the hippocampal-prefrontal cortical circuits impairs spatial working memory performance in rats. Behav. Brain Res. 175: 329-336.

White, I.M. and Wise, S.P. 1999. Rule-dependent neuronal activity in the prefrontal cortex. Exp. Brain Res. 126: 315-335.

Winocur, G. and Eskes, G. 1998. Prefrontal cortex and caudate nucleus in conditional associative learning: Dissociated effects of selective brain lesions in rats. Behav. Neurosci. 112: 89-101.

Witter, M.P. and Amaral, D.G. 2004. The hippocampal formation. In The rat nervous system (ed. G. Paxinos), pp. 635-704. Elsevier, Amsterdam.

Received January 10, 2008; accepted in revised form March 17, 2008. 


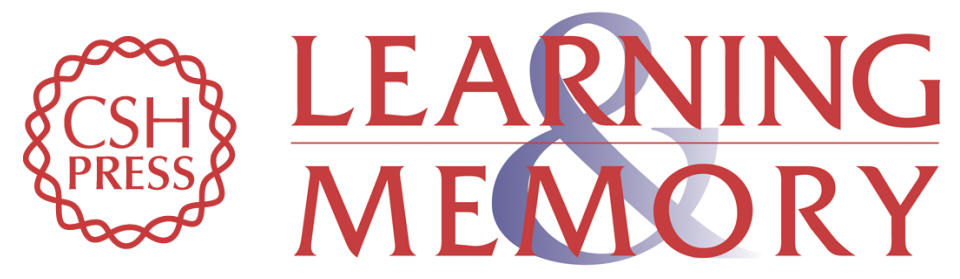

\section{The roles of the medial prefrontal cortex and hippocampus in a spatial paired-association task}

Inah Lee and Frances Solivan

Learn. Mem. 2008, 15:

Access the most recent version at doi:10.1101//m.902708

References This article cites 85 articles, 23 of which can be accessed free at: http://learnmem.cshlp.org/content/15/5/357.full.html\#ref-list-1

License

Email Alerting Receive free email alerts when new articles cite this article - sign up in the box at the Service top right corner of the article or click here. 